\title{
Effects of Roux-en-Y Gastric Bypass and Sleeve Gastrectomy on Bone Mineral Density in Zucker Diabetic Fatty Rats: A Short-Term Comparative Study
}

\author{
Cheng Huang $^{a}$ Qiong Wang ${ }^{b}$ Qin Zhang ${ }^{c}$ Biao Zhou ${ }^{d}$ Jun Lin ${ }^{c}$ Hua Meng ${ }^{d}$ \\ a Department of Orthopedics, China-Japan Friendship Hospital, Beijing, China; ${ }^{b}$ Department of Nephrology, Beijing \\ Hospital, Beijing, China; 'Department of Orthopedics, The First Affiliated Hospital of Soochow University, Suzhou, \\ China; ${ }^{d}$ Department of General Surgery, China-Japan Friendship Hospital, Beijing, China
}

\section{Keywords}

Roux-en-Y gastric bypass · Sleeve gastrectomy $\cdot$ Diabetes mellitus · Bone mineral density $\cdot$ Bone turnover markers

\begin{abstract}
Background: While bariatric surgery could result in weight loss as well as glycaemia improvement, the short-term impact on bone health in a high glycemic environment following Roux-en-Y gastric bypass (RYGB) and sleeve gastrectomy (SG) remains intriguing. Objective: The aim of this study was to compare the short-term effects of RYGB and SG procedures on bone health in Zucker diabetic fatty (ZDFfa/fa) rats. Methods: Thirty age-matched male ZDFfa/fa rats were randomized into RYGB, SG, and sham groups after establishment of the diabetic model. Body weight, blood glucose, bone mineral density (BMD), the level of bone turnover markers (BTM), vitamin D, and serum calcium and phosphorus were measured 4 weeks after the operation. Results: The RYGB procedure brought about lower blood glucose, BMD, serum calcium and phosphorus levels, as well as a relatively higher bone turnover rate and $1,25(\mathrm{OH})_{2} \mathrm{VD}$ level, compared
\end{abstract}

C.H. and Q.W. contributed equally to this work.

karger@karger.com www.karger.com/ofa

Karger

GOPEN ACCESS
(C) 2021 The Author(s)

Published by S. Karger AG, Basel

This is an Open Access article licensed under the Creative Commons Attribution-NonCommercial-4.0 International License (CC BY-NC) (http://www.karger.com/Services/OpenAccessLicense), applicable to the online version of the article only. Usage and distribution for commercial purposes requires written permission. to the SG and sham groups, while the influences of the SG procedure were not significant. $25(\mathrm{OH}) \mathrm{VD}$ demonstrated no significant difference among the 3 groups. Conclusions: Despite its excellent ability to provide short-term glycemic control, the RYGB procedure could led to more severe impairment of bone health compared to the SG procedure. Bone health should be procured after bariatric surgery, especially with the RYGB procedure. Early detection of BMD and BTM may help to avoid deterioration of bone.

\section{(C) 2021 The Author(s)}

Published by S. Karger AG, Basel

\section{Introduction}

Obesity is becoming a global health emergency and it is closely related to a decrease in life expectancy and an increase in social healthcare expenditures. Therefore, it is necessary and beneficial for obese people to lose weight. However, for those with morbid obesity, it is almost impossible to lose weight only by means of lifestyle modifications and pharmacotherapy. Bariatric surgery has been proven to be an effective method for the treatment of

Jun Lin

Department of Orthopedics

The First Affiliated Hospital of Soochow University

Suzhou 215006 (China)

linjun@suda.edu.cn

Hua Meng

Department of General Surgery, China-Japan Friendship Hospital

No. 2, East Yinghua Street

Beijing 100029 (China)

menghuade@hotmail.com 
morbid obesity as well as its associated conditions, such as diabetes mellitus, hypertension, and sleep apnea, among others $[1,2]$. Clinical practice guidelines have recommended bariatric surgery as the most effective method for type 2 diabetes (T2D) patients with a body mass index $(\mathrm{BMI}) \geq 35$ [3]. Among the 6 current dominant bariatric procedures, sleeve gastrectomy (SG) and Roux-en-Y gastric bypass (RYGB) are most commonly used [4]. Despite the evident weight loss effect, bariatric surgery inevitably has some side effects, among which compromised bone health has drawn attention [5].

The underlying mechanisms that mediate bone metabolism after bariatric surgery are still undetermined. Obesity has positive effects on bone health. Increased mechanical loading and strain is one of the possible mechanisms for a higher bone mineral density (BMD) in obesity. Other explanations include that obesity could induce the production of hormones, such as leptin [6], adiponectin [7] and estradiol [8], which have protective effects on bone through the endocrine system. On the contrary, diabetes mellitus has been reported to have a negative effect on bone health because of the reduction of bone resorption (C-terminal cross-linking telopeptide of type I collagen; CTX-1) and formation (procollagen type I N propeptide $[\mathrm{P} 1 \mathrm{NP}]$ and osteocalcin [OC]) markers [9], as well as posttranslational glycation of collagen which could reduce the plasticity of the bone matrix [10].

As restrictive surgeries, both RYGB and SG operations exclude parts of the gastrointestinal tract from alimentation, resulting in the potential development of metabolic deficiencies, including those of calcium and vitamin D. Moreover, a diminished calcium absorption leads to secondary hyperparathyroidism, and all of the above mentioned conditions ultimately lead to bone loss [11].

$\mathrm{BMD}$ is a recognized valid indicator for evaluation of the bone health status. Several studies have reported a decrease in BMD referring to malabsorptive procedures, such as RYGB $[12,13]$. Restrictive procedures do not imply bypassing segments of the small bowel where micronutrient absorption takes place, so that one may expect fewer metabolic disturbances [14]. However, a few studies have reported a progressive increase in BMD in short and long periods after SG [15]. Biochemical markers of bone turnover are other important indicators for estimation of bone loss, and studies have shown a sustainable elevated status in individuals who have undergone bariatric surgery after up to 2 years $[16,17]$. However, little is known about the impact of bariatric surgery on obesity complicated by T2D, especially in the short term. In fact, previous animal and clinical studies have all focused on long-term outcomes after bariatric surgery and short-term outcomes have been ignored. Therefore, this work aims to evaluate the short-term effects of RYGB and SG on bone health in diabetic Zucker diabetic fatty $\left(\mathrm{ZDF}^{\mathrm{fa} / \mathrm{fa}}\right)$ rats.

\section{Materials and Methods}

\section{Experimental Animals}

Thirty age-matched 6 weeks-old male $\mathrm{ZDF}^{\mathrm{fa} / \mathrm{fa}}$ rats and a spontaneous T2D model were purchased from Vital River Laboratories (Beijing, China). The animals were maintained under an artificial 12-h light/12-h dark cycle at room temperature $\left(22-25^{\circ} \mathrm{C}\right)$ and had ad libitum access to Purina 5,008 rat chow (protein, 23\%; fat, 6.5\%; carbohydrates, 58.5\%; fiber, $4 \%$; ash, $8 \%$; and vitamin $\mathrm{D}_{3}, 3.3 \mathrm{IU} / \mathrm{g}$ ) and tap water. Food and water intakes and body weight were recorded daily. One month later, the rats were randomized allocated to the following 3 groups (10 rats/group): RYGB, SG, and sham operated.

The T2D model was confirmed by reaching the target blood glucose (fasting glucose $>11.1 \mathrm{mmol} / \mathrm{L}$ ). The rats were fasted overnight and anesthetized with $2 \%$ isoflurane. Before surgery, the rats were intramuscularly administered $75 \mathrm{mg} / \mathrm{kg}$ ceftriaxone for antimicrobial prophylaxis. All surgeries were performed under sterile conditions.

\section{Surgical Procedures}

The RYGB procedure was performed according to the method of Meguid et al. [18]. Briefly, the stomach was transected 2-3 mm below the gastroesophageal junction, creating a $20 \%$ gastric pouch preserving the vagus nerve. The jejunum was transected $16 \mathrm{~cm}$ distal to the ligament of Treitz, creating a proximal and distal end of small bowel. A 4- to 5-mm end-to-side gastrojejunostomy was anastomosed to the jejunum, creating the alimentary limb. The stump of proximal jejunum was closed by applying a running suture. The side-to-side jejunojejunostomy was sewn $10 \mathrm{~cm}$ below the gastrojejunostomy, and the common limb length was approximately $34 \mathrm{~cm}$ (Fig. 1a).

The SG procedure was carried out as described $[19,20]$. The greater-curvature side of the stomach was vertically dissected including the aglandular forestomach, and a bulldog clamp was placed along the lesser curvature to outline the resected area. The remaining stomach was closed with an invaginating continuous polypropylene (Fig. 1b).

As for the sham-operated group, after performing a 4-cm upper midline incision, the stomach was externalized, manipulated, and returned to the abdomen. Before closure, the abdomen was exposed for a similar period as in other groups.

\section{Postoperative Care}

The rats were kept on a liquid diet with analgesia and prophylactic antibiotics until day 5 using meloxicam $(0.5 \mathrm{mg} / \mathrm{kg}$ of body weight) subcutaneously and doxycycline ( $5 \mathrm{mg} / \mathrm{kg}$ of body weight) mixed with drinking water. The rats were switched back to a Purina 5,008 diet on the sixth day after surgery, and no extra vitamins were supplemented to each group after surgery. Food intake and body weight were monitored at baseline, daily for 1 week postoperatively, and weekly thereafter. Blood glucose levels were measured using a glucose oxidase assay (YSI Life Sciences; Yellow Springs, OH, USA). All blood samples were obtained from the tip 


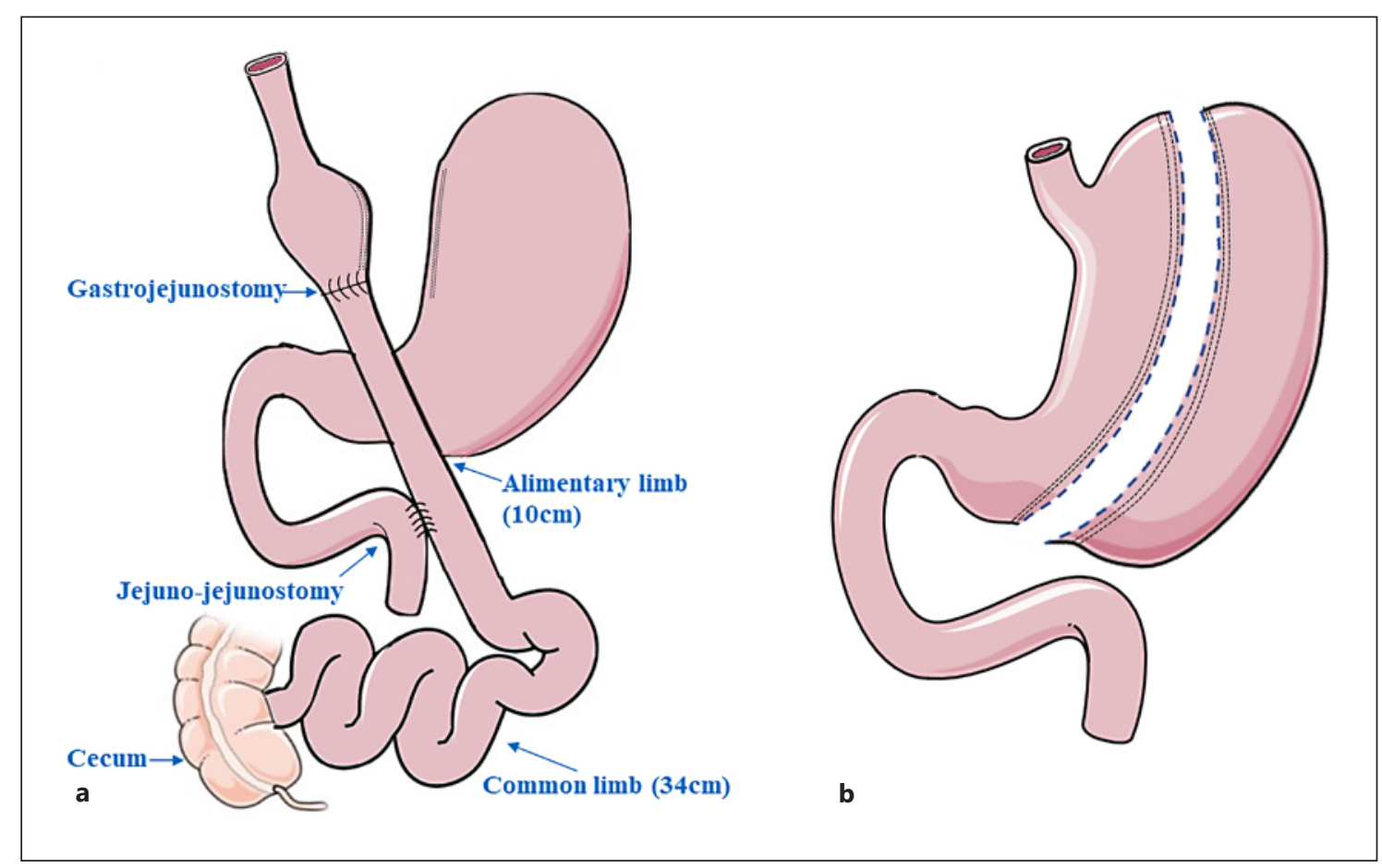

Fig. 1. Schematics of RYGB and SG surgery indicating the new anatomy and limb lengths. a RYGB. b SG.

of the tail vein after a 6-h fast. After centrifugation, plasma was immediately separated and stored at $-80^{\circ} \mathrm{C}$ for further exploration. One rat in the SG group and 3 rats in the sham group died after the operation, unfortunately.

\section{Execution and Sample Collection}

Four weeks after surgery, blood samples were collected prior to sacrification of the rats. Specifically, the rats were killed by decapitation under anesthesia. Blood samples of each rats were drawn from the aorta, collected in an ethylenediamine tetra-acetic acid (EDTA) tube, and stored at $-20^{\circ} \mathrm{C}$ for further analysis after overnight fasting. The spine and femur were carefully detached and soft tissue was stripped and then fixed in $10 \%$ formalin for further processing.

Assessment of Serum Calcium, Phosphorus, and Bone

Turnover Markers

Serum total calcium and phosphorus were measured using the chemistry analyzer Cobas Integra 800 (Japanese Olympus automatic biochemical instrument AU480). Serum 25(OH)VD, $1,25(\mathrm{OH}) 2 \mathrm{VD}$, rat P1NP, CTX-1, and OC were measured by enzyme-linked immunosorbent assay (ELISA; Multiskan MK3; Thermo, USA).

\section{Micro-Computed Tomography Analysis}

Four weeks after surgery, the BMD of the right distal femur and the fifth lumbar vertebra were scanned using a desktop microtomographic imaging system (SkyScan 1,176; Aartselaar, Belgium). Micro-computed tomography $(\mu \mathrm{CT})$ imaging parameters were listed as follows: resolution, $9 \mu \mathrm{m}$; and X-ray energy, $80 \mathrm{kV}$ and 100
mA. Each scan took about 15 min. For quantification, the region of interest was selected as follow: a cancellous region from 15 to $25 \%$ of the femur length from the distal end. From $100 \mu \mathrm{CT}$ slices of the cancellous vertebral bone and cancellous region of interest of the distal femur, BMD, the bone volume-to-total volume ratio (BV/TV), trabecular thickness (Tb.Th), trabecular separation (Tb. $\mathrm{Sp})$, trabecular number (Tb.N), trabecular bone pattern formation (Tb.Pf), the bone surface-to-total volume ratio (BS/TV), and the structural model index (SMI) were analyzed using a SkyScan computed tomography (CT) analyzer. The SMI is an index for determining the plate- or rod-like geometry of trabecular structures. For an ideal plate and rod structure, the SMI value is 0 and 3, respectively. For a structure with both plates and rods of equal thickness, the value lies between 0 and 3 , depending on the volume ratio of rods and plates. All $\mu \mathrm{CT}$ parameters were reported according to international guidelines.

The scanned lumbar vertebrae and right distal femurs were reconstructed into a 3-dimensional structure using NRecon software (Micro Photonics, Inc.). The 3-D bone volume including phalanges and metatarsal bones was quantified using CTAn software (Bluescientific, Inc.) to evaluate the volumetric change in lumbar vertebrae and distal femurs in a quantitative way. 3-D models of lumbar vertebrae and distal femurs were modified using Mimics Research 19.0 software (Materialise, Inc.).

\section{Statistical Analysis}

Data were presented as mean \pm SD and analyzed using SPSS version 24 (IBM Corporation, Somers, NY, USA). Data were tested for normality and homogeneity of variance before assessment by single-factor analysis of variance (ANOVA) or the Fisher least 
Fig. 2. Weekly food intake over the study

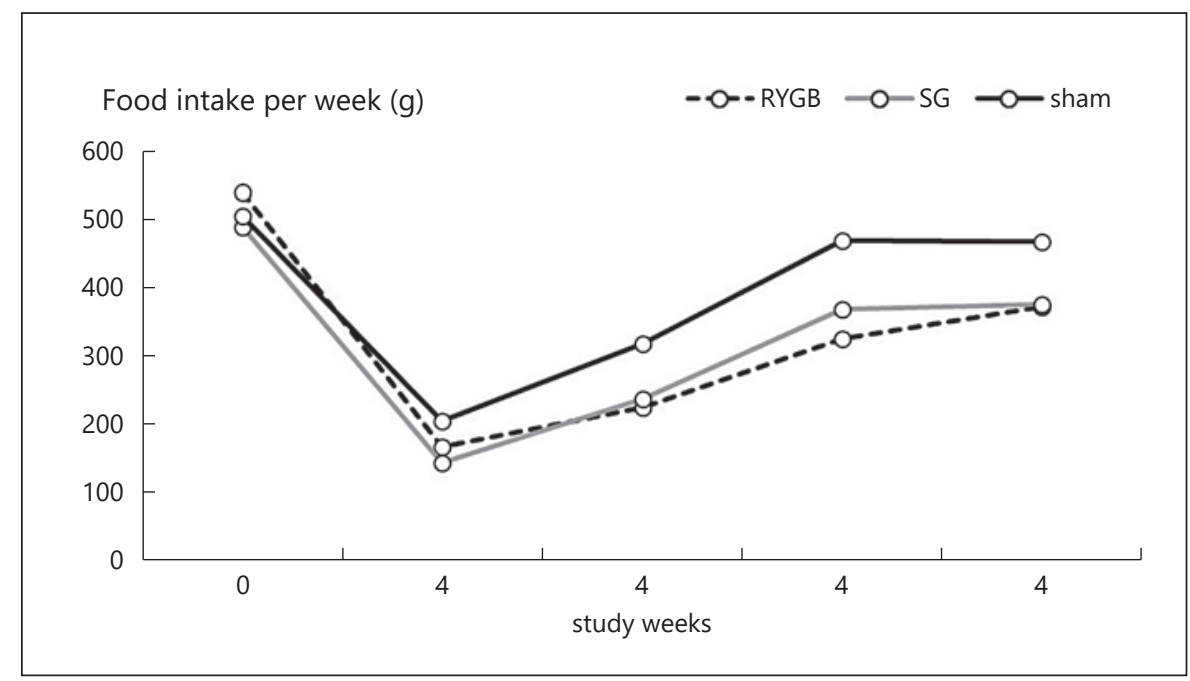
duration.

Table 1. Baseline and 4-week postoperative characteristics

\begin{tabular}{|c|c|c|c|c|}
\hline Characteristic & Weight, g & $\begin{array}{l}\text { Glucose, } \\
\mathrm{mmol} / \mathrm{L}\end{array}$ & $\begin{array}{l}\text { Calcium, } \\
\mathrm{mmol} / \mathrm{L}\end{array}$ & $\begin{array}{l}\text { Phosphate, } \\
\mathrm{mmol} / \mathrm{L}\end{array}$ \\
\hline \multicolumn{5}{|l|}{ Baseline } \\
\hline RYGB group & $385.1 \pm 30.5$ & $22.49 \pm 4.58$ & $2.50 \pm 0.18$ & $03.05 \pm 0.31$ \\
\hline SG group & $374.9 \pm 29.4$ & $23.37 \pm 5.84$ & $2.51 \pm 0.20$ & $02.91 \pm 0.36$ \\
\hline Sham group & $379.7 \pm 35.7$ & $22.89 \pm 5.08$ & $2.55 \pm 0.22$ & $03.20 \pm 0.52$ \\
\hline$p$ value & $0.782^{\mathrm{a}}$ & $0.935^{\mathrm{a}}$ & $0.875^{\mathrm{a}}$ & $0.363^{\mathrm{a}}$ \\
\hline \multicolumn{5}{|l|}{ Final } \\
\hline RYGB group & $369.4 \pm 34.4$ & $14.34 \pm 9.42$ & $2.27 \pm 0.09$ & $02.20 \pm 0.42$ \\
\hline SG group & $373.2 \pm 39.9$ & $19.47 \pm 8.07$ & $2.47 \pm 0.18$ & $03.02 \pm 0.77$ \\
\hline Sham group & $412.9 \pm 31.9$ & $25.89 \pm 7.44$ & $2.66 \pm 0.26$ & $03.34 \pm 0.81$ \\
\hline$p$ value & $0.047^{*, \mathrm{a}}$ & $0.037^{\mathrm{a}}$ & $0.003^{\mathrm{b}}$ & $0.006^{\mathrm{b}}$ \\
\hline \multicolumn{5}{|l|}{$\begin{array}{l}p \text { value for multiple } \\
\text { comparisons }\end{array}$} \\
\hline RYGB vs. SG & $0.815^{\mathrm{c}}$ & $0.201^{\mathrm{c}}$ & $0.024^{*, \mathrm{~d}}$ & $0.036^{*, \mathrm{~d}}$ \\
\hline SG vs. sham & $0.021^{*, \mathrm{c}}$ & $0.146^{\mathrm{c}}$ & $0.264^{\mathrm{d}}$ & $0.712^{\mathrm{d}}$ \\
\hline RYGB vs. sham & $0.038^{*, \mathrm{c}}$ & $0.011^{*, \mathrm{c}}$ & $0.014^{*, \mathrm{~d}}$ & $0.021^{*, \mathrm{~d}}$ \\
\hline
\end{tabular}

${ }^{*} p<0.05 .{ }^{\mathrm{a}}$ One-way ANOVA. ${ }^{\mathrm{b}}$ Welch test. ${ }^{\mathrm{c}}$ LSD test. ${ }^{\mathrm{d}}$ Games-Howell test.

significant difference test. The Welch test for ANOVA or the Games-Howell test was performed when homogeneity of variance was not met. $p<0.05$ was considered statistically significant.

\section{Results}

Food Intake, Blood Glucose, Serum Calcium and Phosphorus, and Body Weight

Mean weekly chow consumptions were similar among different animal groups at baseline. Both the
RYGB group and the SG group showed a consistent decrease in food intake compared with the sham group, especially in the first few days after surgery, while the difference in food intake between RYGB and SG was not obvious (Fig. 2). There was no significant difference among the 3 groups in terms of blood glucose, serum calcium and phosphorus, or body weight. Twenty-eight days after surgery, significantly lower fasting plasma glucose levels were observed in the RYGB group $(p<$ 0.05 ) compared to the sham group, while no significant 


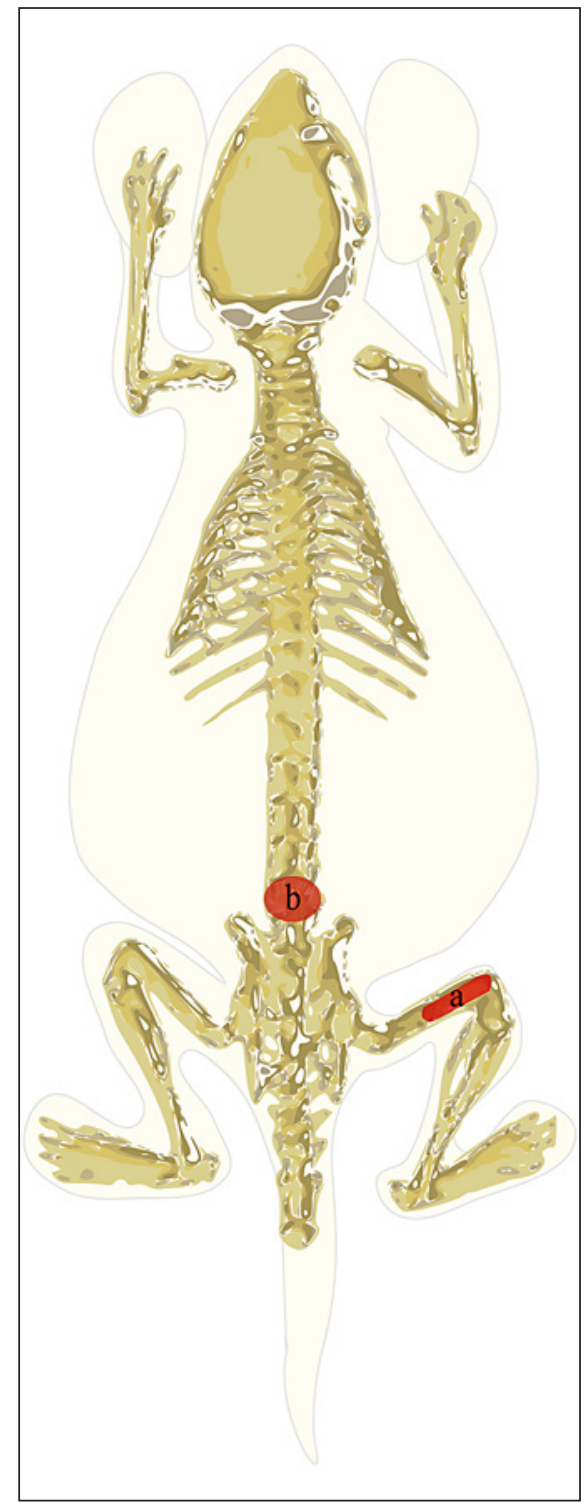

Fig. 3. General view of the right distal femur (a) and the fifth lumbar vertebra (b) in relation to the rest of the rat skeleton.

difference was noticed between the RYGB group and the SG group. The RYGB group had a more obvious decline in serum calcium and phosphorus levels compared to the SG group and the sham group, while no significant difference was noticed between the SG group and the sham group. Both the RYGB group and the SG group demonstrated a steady and continuous weight loss postoperatively compared to the sham group; differences between the 2 bariatric procedures were not significant (Table 1).

\section{$B M D$ and Bone Variables}

Figure 3 showed the general view of a rat right distal femur and fifth lumbar vertebrae in relation to the rest of the skeleton. The BMD of the distal femur and spine were both significantly lower in the RYGB group than that in the sham group $(p<0.005)$, while only a significant lower $\mathrm{BMD}$ of the spine was detected in the RYGB group compared to the SG group $(p<0.05)$. $\mu$ CT scan images of sagittal distal femurs and L5 vertebrae and their corresponding 3-D reconstructions are shown in Figures 4 and 5, respectively. The bone microstructure of the distal femur became sparse in both bariatric groups (Fig. 4). Osteopenia of L5 vertebrae was only seen in the RYGB group, which vindicated that overall bone health was impaired after bariatric surgery, especially after the RYGB procedure (Fig. 5).

Further evaluation was conducted to quantify bone health based on bone variables measured by $\mu \mathrm{CT}$. Almost all of the bone variables of both the distal femur and the spine indicated a more significant loss of bone quality and bone mass in the RYGB group compared to the sham group, except for BS/TV of the spine. Meanwhile, BV/TV, Tb.Th, Tb.N, Tb.Pf, BS/TV, and SMI of the distal femur showed a significant difference when compared with the values of the SG group. The SG group exhibited a much lower BMD of the distal femur compared to the sham group $(p<0.05)$, while no significant difference was detected in the BMD of spine. BV/TV, Tb.Sp, and Tb.Pf of the spine and BV/TV of the distal femur demonstrated significant differences between the SG group and the sham group (Tables 2,3 ).

\section{Bone Turnover Markers and Vitamin D}

Generally, bone turnover markers (BTM) were relatively higher in the RYGB group and the SG group than in the sham group (Table 4). As a bone resorptive marker, significant higher CTX-1 levels were found in the RYGB and SG groups compared to the sham group (RYGB vs. sham group: $p<0.01$; SG vs. sham group: $p<0.05$ ), and the CTX-1 level in the RYGB group was slightly higher than that in the SG group. For bone formation markers, P1NP in the RYGB group exhibited the highest level among the 3 groups, whereas disparity was only apparent between the RYGB group and the sham group $(p<0.05)$. Unlike for CTX-1 and P1NP, there were no differences among the 3 groups in terms of OC.

The vitamin $\mathrm{D}$ level was also tested in vivo. The level of $25(\mathrm{OH}) \mathrm{VD}$ in the RYGB group was the lowest among the 3 groups, though without a significant difference. However, level of $1,25(\mathrm{OH}) 2 \mathrm{VD}$ in the RYGB group showed 

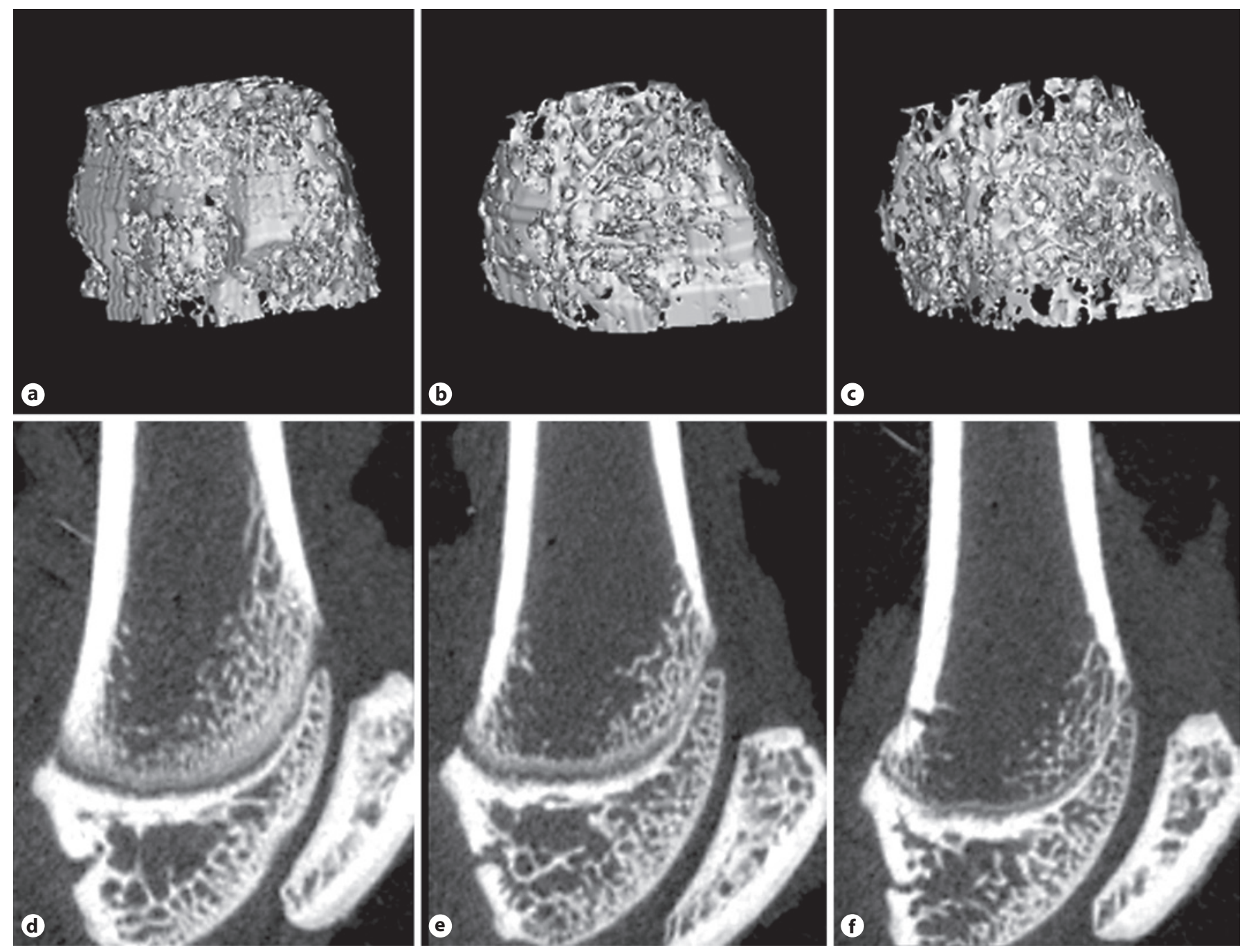

Fig. 4. Sagittal images of distal femurs for the sham (d), SG (e), and RYGB (f) groups. Corresponding 3-D reconstructions for the sham (a), SG (b), and RYGB (c) groups.

the opposite results, i.e., was evidently higher compared to that of the sham group $(p<0.05)$. Fibroblast growth factor-23 (FGF23) is a phosphate regulating hormone that can be upregulated in the circumstance of a high blood vitamin D level. Interestingly, the lowest level of FGF23 was seen in the RYGB group among the 3 groups (RYGB vs. sham group: $p<0.005$; RYGB vs. SG group: $p<0.05)$.

\section{Discussion}

We performed a short-term investigation on bone metabolism changes after 2 of the most widely used bariatric procedures in obese rats with T2D models. As expected, the RYGB procedure had a rapid and effective impact on glycemic control, while the SG procedure did not. Both the RYGB group and the SG group showed a trend toward weight loss after bariatric surgery, though no statistical significance was observed in the short term. A meta-analysis including 16 RCT with a total of 1,132 patients revealed that the RYGB procedure was more effective than SG in terms of weight loss and short-term glycemic control in patients with and without T2D [21]. Wang et al. [22] compared the effects of the RYGB and SG procedures in ZDF rats and found that the RYGB group had a greater weight loss than the SG group every week and better glucose control 5 weeks after the operation. Our observational 


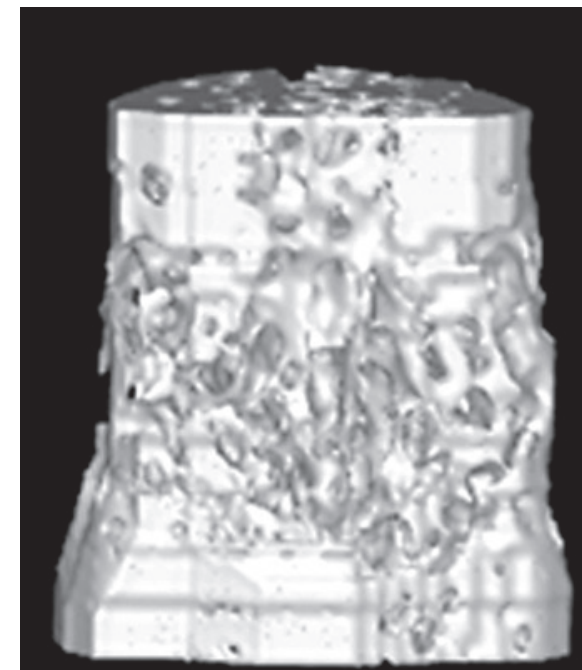

a

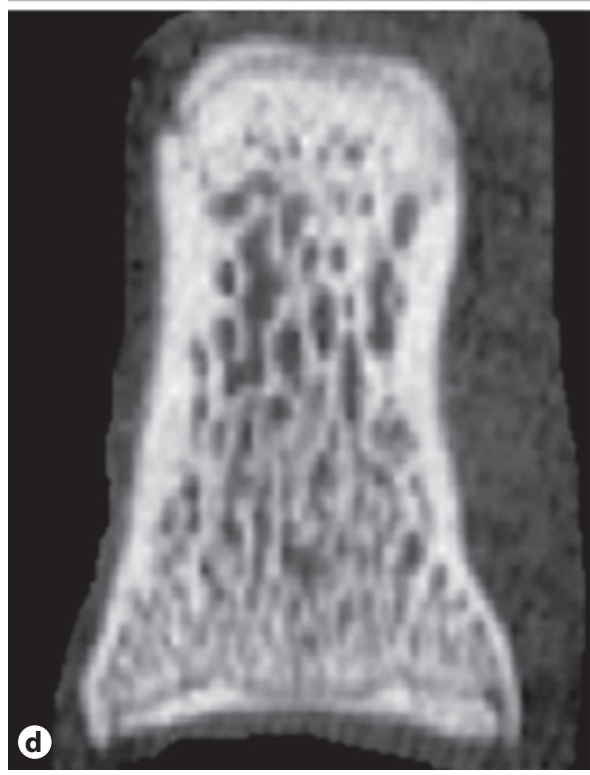

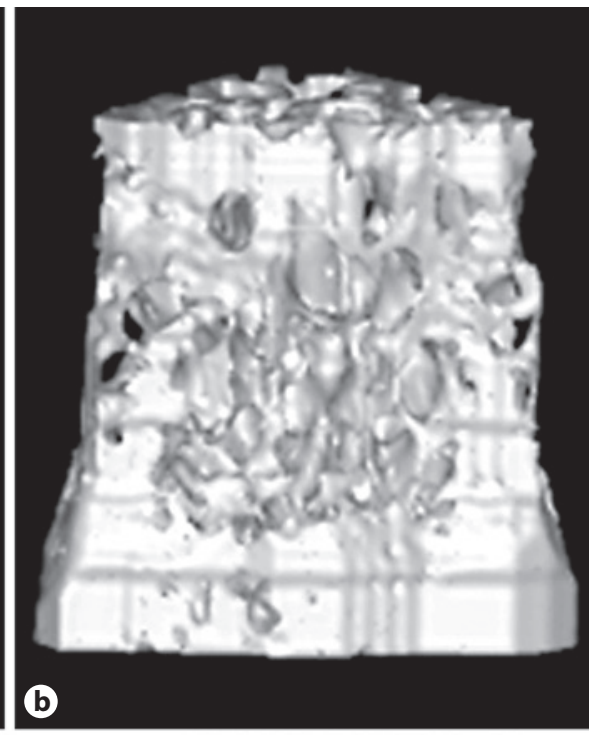
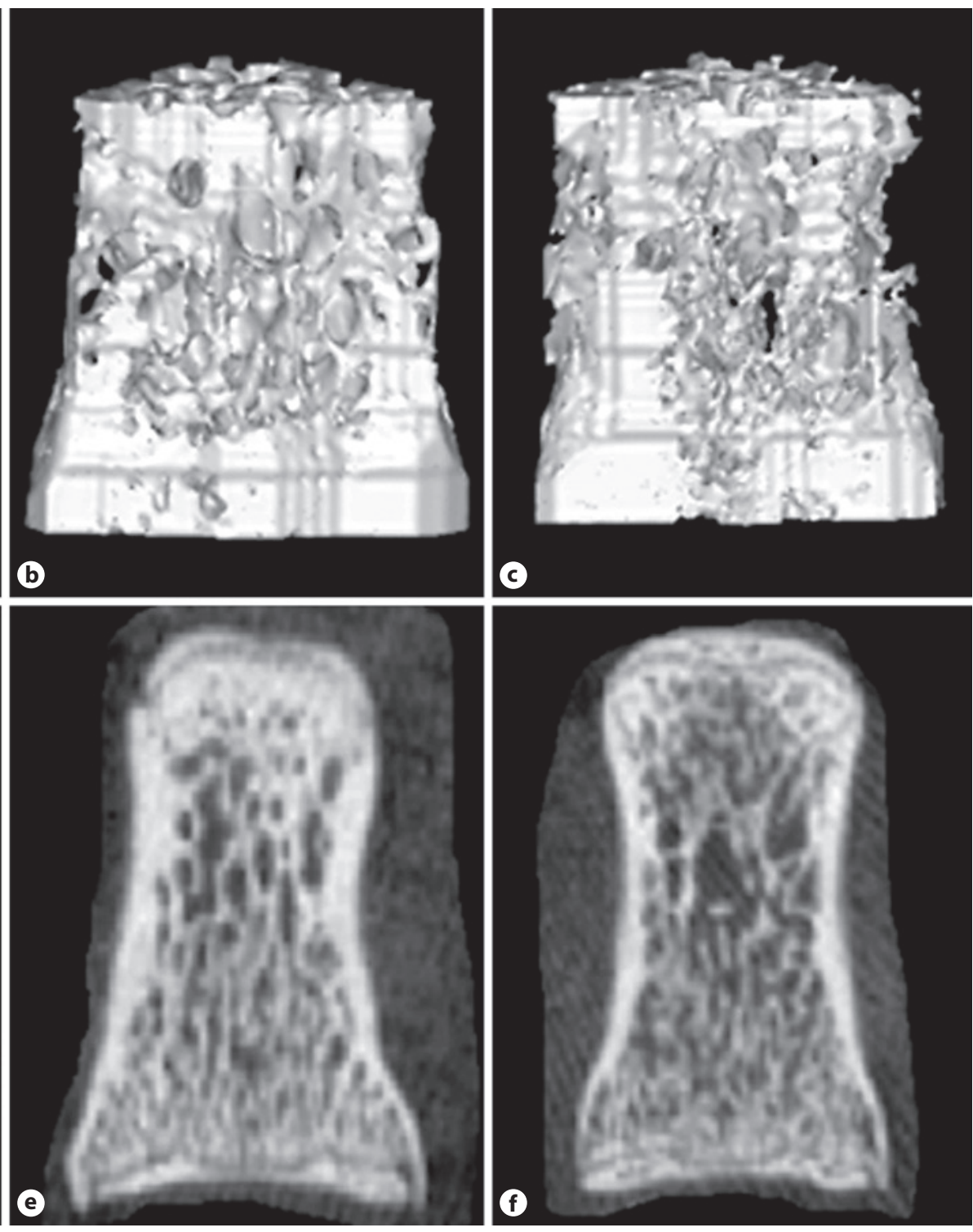

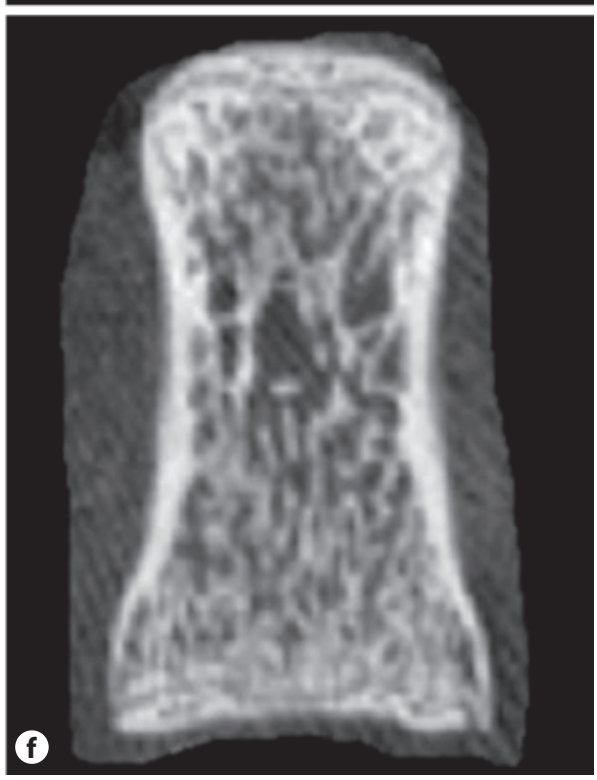

Fig. 5. Sagittal images of the L5 vertebrae for the sham (d), SG (e), and RYGB (f) groups. Corresponding 3-D reconstruction for the sham $(\mathbf{a}), \mathrm{SG}(\mathbf{b})$, and RYGB (c) groups.

findings in animal models further support the previous conclusions.

So far, there is no unified measurement of BMD. Since dual energy X-ray (DXA) cannot accurately measure the changes in adipose tissue density and distribution following bariatric surgery [23], $\mu \mathrm{CT}$ was selected to evaluate the volumetric BMD in our study. Moreover, $\mu \mathrm{CT}$ has the advantage of distinguishing bone trabecula, cortex, and other bone parameters [24, 25]. A decreased BMD was noticed in both bariatric surgery groups within 4 weeks after the operation, especially the spinal BMD in the RYGB group. Studies with the same results attributed the discrepancy to the setting of obesity and a changing body composition during BMD measurement [26]. According to our results, malabsorption of calcium and vitamin D, instead of body weight loss, presumably played a more important role in the decline of spinal BMD in $\mathrm{ZDF}^{\mathrm{fa} / \mathrm{fa}}$ rats because RYGB could compromise the absorption of calcium and vitamin D. A decreased BMD indicates impaired bone health. Therefore, our results indicated a full 
Table 2. Comparisons of BMD and bone variables on distal femurs among the 3 groups

\begin{tabular}{|c|c|c|c|c|c|}
\hline Distal femur & $\begin{array}{l}\text { RYGB group } \\
(n=10)\end{array}$ & $\begin{array}{l}\text { SG group } \\
(n=9)\end{array}$ & $\begin{array}{l}\text { Sham group } \\
(n=7)\end{array}$ & $F(p$ value $)$ & $\begin{array}{l}p \text { value for multiple com- } \\
\text { parisons }\end{array}$ \\
\hline $\mathrm{vBMD}, \mathrm{g} / \mathrm{cm}^{3}$ & $0.547 \pm 0.308$ & $0.571 \pm 0.294$ & $0.603 \pm 0.203$ & $8.129(0.002)^{*, a}$ & $\begin{array}{l}\text { RYGB vs. SG } 0.075^{c} \\
\text { SG vs. sham } 0.035^{*, c} \\
\text { RYGB vs. sham } 0.001^{*, c}\end{array}$ \\
\hline $\mathrm{BV} / \mathrm{TV}, \%$ & $26.19 \pm 5.65$ & $34.40 \pm 4.94$ & $41.89 \pm 8.42$ & $13.088(0.000)^{*, \mathrm{a}}$ & $\begin{array}{l}\text { RYGB vs. SG } 0.009^{*, c} \\
\text { SG vs. sham } 0.027^{*, c} \\
\text { RYGB vs. sham } 0.000^{*, c}\end{array}$ \\
\hline Tb.Th, mm & $0.141 \pm 0.127$ & $0.158 \pm 0.085$ & $0.179 \pm 0.249$ & $9.377(0.003)^{*, \mathrm{~b}}$ & $\begin{array}{l}\text { RYGB vs. SG } 0.008^{*, \mathrm{~d}} \\
\text { SG vs. sham } 0.154^{\mathrm{d}} \\
\text { RYGB vs. sham } 0.014^{*, \mathrm{~d}}\end{array}$ \\
\hline Tb.Sp, mm & $0.797 \pm 0.139$ & $0.700 \pm 0.162$ & $0.599 \pm 0.153$ & $3.575(0.044)^{*, \mathrm{a}}$ & $\begin{array}{l}\text { RYGB vs. SG } 0.174^{c} \\
\text { SG vs. sham } 0.198^{c} \\
\text { RYGB vs. sham } 0.014^{*, c}\end{array}$ \\
\hline Tb.N, $\mathrm{mm}^{-1}$ & $1.84 \pm 0.26$ & $2.17 \pm 0.23$ & $2.33 \pm 0.22$ & $9.195(0.001)^{*, a}$ & $\begin{array}{l}\text { RYGB vs. SG } 0.007^{*, c} \\
\text { SG vs. sham } 0.206^{c} \\
\text { RYGB vs. sham } 0.000^{*, c}\end{array}$ \\
\hline Tb.Pf, $\mathrm{mm}^{-1}$ & $-1.15 \pm 2.01$ & $-4.45 \pm 1.52$ & $-6.37 \pm 2.62$ & $14.348(0.000)^{*, \mathrm{a}}$ & $\begin{array}{l}\text { RYGB vs. SG } 0.002^{*, c} \\
\text { SG vs. sham } 0.075^{c} \\
\text { RYGB vs. sham } 0.000^{*, c}\end{array}$ \\
\hline $\mathrm{BS} / \mathrm{TV}, \%$ & $6.53 \pm 0.71$ & $7.42 \pm 0.65$ & $7.64 \pm 0.48$ & $7.559(0.003)^{*, a}$ & $\begin{array}{l}\text { RYGB vs. SG } 0.006^{*, c} \\
\text { SG vs. sham } 0.499^{c} \\
\text { RYGB vs. sham } 0.002^{*, c}\end{array}$ \\
\hline SMI & $1.172 \pm 0.303$ & $0.682 \pm 0.253$ & $0.724 \pm 0.568$ & $11.704(0.001)^{*, \mathrm{~b}}$ & $\begin{array}{l}\text { RYGB vs. SG } 0.004^{*, d} \\
\text { SG vs. sham } 0.135^{\mathrm{d}} \\
\text { RYGB vs. sham } 0.004^{*, \mathrm{~d}}\end{array}$ \\
\hline
\end{tabular}

Fig. 6. Mechanism of the G-CSF effect on

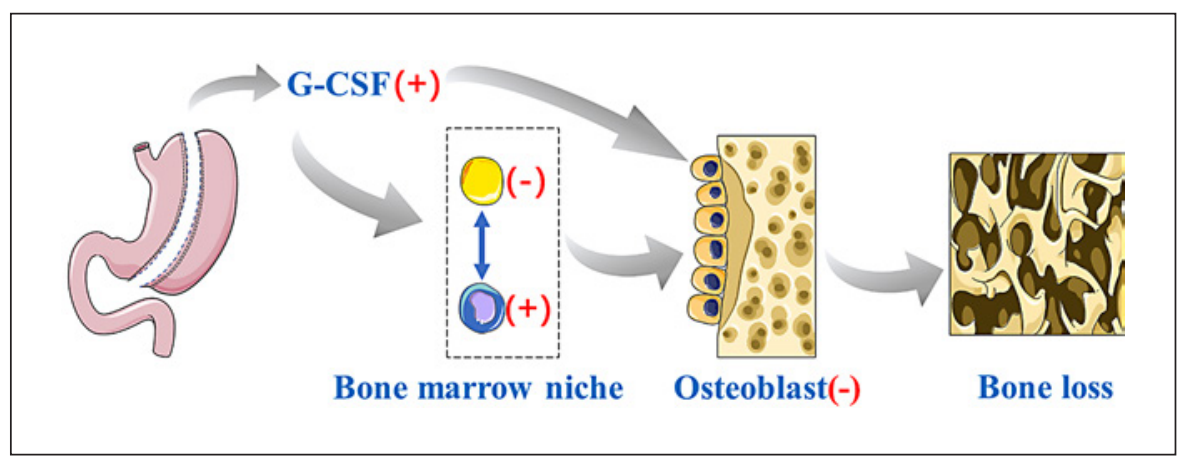
bone after the SG procedure.

decrease in both bone quality (Tb.Th, Tb.Pf, SMI) and quantity (BV/TV, Tb.Sp, Tb.N, BS/TV) in the RYGB group, while osteopenia just began to appear in the SG group, especially in the distal femur.

From the current point of view, bariatric surgery has side effects on human bone health [27]. Almost all studies have concluded that the BMD of the distal femur will decrease after bariatric surgery, with an average follow-up time ranging from 6 months $[28,29]$ to 1 year [30] or 5 years [31], and bone health deteriorates further over time [32]. However, to date, studies comparing RYGB and SG and their effects on BMD have shown conflicting results. 
Table 3. Comparison of BMD and bone variables in L5 vertebrae among the 3 groups

\begin{tabular}{|c|c|c|c|c|c|}
\hline Spine & $\begin{array}{l}\text { RYGB group } \\
(n=10)\end{array}$ & $\begin{array}{l}\text { SG group } \\
(n=9)\end{array}$ & $\begin{array}{l}\text { Sham group } \\
(n=7)\end{array}$ & $\mathrm{F}, p$ value & $\begin{array}{l}p \text { value for multiple } \\
\text { comparisons }\end{array}$ \\
\hline $\mathrm{vBMD}, \mathrm{g} / \mathrm{cm}^{3}$ & $0.531 \pm 0.323$ & $0.568 \pm 0.297$ & $0.601 \pm 0.412$ & $8.874,0.001^{*, a}$ & $\begin{array}{l}\text { RYGB vs. SG } 0.026^{*, c} \\
\text { SG vs. sham } 0.070^{c} \\
\text { RYGB vs. sham } 0.000^{*, c}\end{array}$ \\
\hline $\mathrm{BV} / \mathrm{TV}, \%$ & $45.39 \pm 5.38$ & $50.28 \pm 4.42$ & $59.46 \pm 8.61$ & $10.939,0.000^{*, \mathrm{a}}$ & $\begin{array}{l}\text { RYGB vs. SG } 0.095^{c} \\
\text { SG vs. sham } 0.007^{*, c} \\
\text { RYGB vs. sham } 0.000^{*, c}\end{array}$ \\
\hline Tb.Th, mm & $0.150 \pm 0.013$ & $0.161 \pm 0.011$ & $0.185 \pm 0.030$ & $5.262,0.022^{*, b}$ & $\begin{array}{l}\text { RYGB vs. SG } 0.107^{\mathrm{d}} \\
\text { SG vs. sham } 0.174^{\mathrm{d}} \\
\text { RYGB vs. sham } 0.045^{*, \mathrm{~d}}\end{array}$ \\
\hline Tb.Sp, mm & $0.237 \pm 0.022$ & $0.227 \pm 0.026$ & $0.196 \pm 0.026$ & $6.0710 .008^{*, a}$ & $\begin{array}{l}\text { RYGB vs. SG } 0.358^{c} \\
\text { SG vs. sham } 0.020^{*, c} \\
\text { RYGB vs. sham } 0.002^{*, c}\end{array}$ \\
\hline Tb.N, $\mathrm{mm}^{-1}$ & $3.02 \pm 0.18$ & $3.12 \pm 0.11$ & $3.11 \pm 0.16$ & $4.132,0.029^{*, a}$ & $\begin{array}{l}\text { RYGB vs. SG } 0.133^{c} \\
\text { SG vs. sham } 0.183^{c} \\
\text { RYGB vs. sham } 0.009^{*, c}\end{array}$ \\
\hline Tb.Pf, $\mathrm{mm}^{-1}$ & $-3.93 \pm 1.05$ & $-4.83 \pm 1.05$ & $-7.23 \pm 2.12$ & $8.935,0.001^{*, a}$ & $\begin{array}{l}\text { RYGB vs. SG } 0.236^{c} \\
\text { SG vs. sham } 0.007^{*, c} \\
\text { RYGB vs. sham } 0.000^{*, c}\end{array}$ \\
\hline $\mathrm{BS} / \mathrm{TV}, \%$ & $9.77 \pm 0.34$ & $9.91 \pm 0.21$ & $10.01 \pm 0.50$ & $0.992,0.386^{\mathrm{a}}$ & - \\
\hline SMI & $0.495 \pm 0.348$ & $0.293 \pm 0.215$ & $-0.360 \pm 0.633$ & $5.078,0.025^{*, b}$ & $\begin{array}{l}\text { RYGB vs. SG } 0.302^{\mathrm{d}} \\
\text { SG vs. sham } 0.078^{\mathrm{d}} \\
\text { RYGB vs. sham } 0.026^{*, \mathrm{~d}}\end{array}$ \\
\hline
\end{tabular}

Table 4. Comparison of bone turnover markers and vitamin D among the 3 groups

\begin{tabular}{|c|c|c|c|c|c|c|c|}
\hline & Number & $\begin{array}{l}\text { FGF23, } \\
\mathrm{pg} / \mathrm{mL}\end{array}$ & $\begin{array}{l}1,25(\mathrm{OH})_{2} \mathrm{VD} \\
\mathrm{ng} / \mathrm{mL}\end{array}$ & $\begin{array}{l}25(\mathrm{OH}) \mathrm{VD}, \\
\mathrm{pg} / \mathrm{mL}\end{array}$ & $\begin{array}{l}\text { CTX-1, } \\
\mathrm{pg} / \mathrm{mL}\end{array}$ & $\begin{array}{l}\mathrm{OC}, \\
\mathrm{pg} / \mathrm{mL}\end{array}$ & $\begin{array}{l}\mathrm{P} 1 \mathrm{NP}, \\
\mathrm{pg} / \mathrm{mL}\end{array}$ \\
\hline RYGB group & 10 & $15.00 \pm 4.31$ & $2.58 \pm 0.75$ & $189.43 \pm 54.71$ & $32.30 \pm 11.50$ & $1.50 \pm 0.38$ & $212.76 \pm 74.59$ \\
\hline SG group & 9 & $19.16 \pm 3.26$ & $2.01 \pm 0.71$ & $196.13 \pm 53.70$ & $28.43 \pm 9.03$ & $1.44 \pm 0.23$ & $183.23 \pm 60.28$ \\
\hline Sham group & 7 & $21.32 \pm 2.69$ & $1.70 \pm 0.58$ & $229.15 \pm 48.08$ & $17.88 \pm 7.05$ & $1.40 \pm 0.24$ & $131.37 \pm 24.55$ \\
\hline$F(p$ value $)$ & & $6.935(0.004)^{*, \mathrm{a}}$ & $3.575(0.044)^{*, \mathrm{a}}$ & $1.268(0.300)^{\mathrm{a}}$ & $4.730(0.019)^{*, \mathrm{a}}$ & $0.194(0.826)^{b}$ & $3.804(0.037)^{*, a}$ \\
\hline \multicolumn{8}{|c|}{$p$ value for multiple comparisons } \\
\hline RYGB vs. SG & & $0.019 *, \mathrm{c}$ & $0.087^{\mathrm{c}}$ & - & $0.393^{\mathrm{c}}$ & - & $0.295^{\mathrm{c}}$ \\
\hline SG vs. sham & & $0.245^{\mathrm{c}}$ & $0.385^{\mathrm{c}}$ & & $0.041^{*, \mathrm{c}}$ & & $0.100^{\mathrm{c}}$ \\
\hline RYGB vs. sham & & $0.002^{*, c}$ & $0.017^{*, \mathrm{c}}$ & & $0.006^{*, c}$ & & $0.011^{*, \mathrm{c}}$ \\
\hline
\end{tabular}

${ }^{*} p<0.05 .{ }^{a}$ One-way ANOVA. ${ }^{\mathrm{b}}$ Welch test. ${ }^{\mathrm{c}}$ LSD test. ${ }^{\mathrm{d}}$ Games-Howell test. CTX, C-terminal cross-linking telopeptide of type I collagen; P1NP, procollagen type I N propeptide.

Most studies suggested that there is a decreased BMD in the spine after RYGB and SG procedures [13, 32, 33], while some studies showed no change in $\operatorname{BMD}[33,34]$ and another study even showed an increased BMD fol- lowing SG [15]. A study of 80 patients undergoing RYGB and SG suggested no significant differences in hip and spine BMD between RYGB and SG 1 year after surgery [35]. Nevertheless, Bredella et al. [36] indicated acceler- 
ated bone loss in 21 patients at the distal femur 1 year after RYGB compared to SG using DXA, although no significant difference in the spine was detected by $\mu \mathrm{CT}$.

The mechanisms impacting BMD after bariatric surgery are multifactorial. Some studies have pointed out that the decrease in BMD is associated with the extent of weight loss [34]; however, our short-term investigation did not notice a significant difference in weight loss between the 2 groups. Abegg et al. [37] conducted a weightmatched study and obtained similar results, i.e., that the mechanism of bone loss after RYGB was not directly caused by weight loss in rats. The impaired and limited absorption of calcium and vitamin D maybe the key determinant to a lower BMD after RYGB. Mechanical unloading may play a more important role in bone health in the SG group rather than in RYGB group [36]. Since we conducted a short-term investigation, the impact of weight loss may not fully have been enough to affect the outcome of BMD, especially in weight-bearing areas. A recent study suggested that granulocyte colony-stimulating factor (G-CSF) could partially explain the possible mechanism. The G-CSF level has been found to be elevated after the SG procedure; though it is not the dominant factor, it could have an intermediary role on bone loss by impacting the bone marrow niche (Fig. 6) [38]. Because hyperglycemia is detrimental to the bone structure, diabetes may be another factor affecting BMD results in our study. However, the fact is that BMD increases in most T2D patients [39]. The reason may be that almost all patients with T2D are obese. Together with our results, a lower blood glucose level may not play a key role in resisting $\mathrm{BMD}$ reduction after bariatric surgery.

BTM are proteins or protein derivative biomarkers released by osteoblasts or osteoclasts during bone remodeling. They have a prognostic role in fracture risk evaluation which could be supplemental to radiography [40]. As can be inferred from our study, a greater increase in the bone turnover rate was noted in the RYGB group compared to the SG group. More specifically, a much higher level of the bone resorption marker CTX-1 was noticed after both bariatric surgeries. In the meantime, only P1NP, i.e., one of the tested 2 bone formation markers, was higher after the RYGB procedure, and the other marker, i.e., OC, was not significantly different among the 3 groups. Generally, bone resorption and formation are in a dynamic equilibrium. From our point of view, bariatric surgery can make this balance more inclined to bone absorption in the early stage, especially after RYGB surgery, which can partly explain the significant reduction of BMD in the RYGB group.

Effects of RYGB and SG on BMD in

$\mathrm{ZDF}^{\mathrm{fa} / \mathrm{fa}}$ Rats: Short-Term Comparison
It is generally recognized that bariatric surgery can increase the bone turnover rate [41]. The elevation of serum CTX-1 could occur as early as day 10 [42] and peak at 6-12 months [42, 43]. Likewise, bone formation markers increase, but at lower levels. These findings indicate that the overall net effect can lead to postoperative bone loss as well. Few studies have compared the effects of RYGB and SG on BTM. A 5-year follow-up RCT involving 95 patients with obesity and T2D showed that CTX-1 and OC increased following RYGB and, to a lesser extent, in SG patients [44]. Another study showed a comparable increase for these 2 procedures [43].

Bariatric surgery impaired calcium and vitamin D absorption as a result of food intake restriction and malabsorption, an effect that may bring about bone loss. In our observation, blood calcium and phosphorus decreased obviously 4 weeks after the RYGB procedure but not after the SG procedure. Along with blood calcium, the level of $25(\mathrm{OH})$ VD showed a declining trend. Thus, our finding supports the viewpoint that early and sufficient calcium and vitamin D supplements are required after RYGB surgery. Even though levels of serum calcium, phosphorus, and $25(\mathrm{OH}) \mathrm{VD}$ have been reported to be decreased in obese patients [45], a series of studies found no differences $[32,46]$. One explanation is that vitamin D is usually stored in adipose tissue, and thus obesity means a bigger pool to store more vitamin D. With body weight loss, vitamin D is released from the adipose tissue [47]. However, due to the relatively short observation time in our study, body weight loss was not evident and therefore vitamin $\mathrm{D}$ stored in adipose tissue may not have compensated for the serum level in time.

The level of $1,25(\mathrm{OH}) 2 \mathrm{VD}$, which is the active form of $25(\mathrm{OH}) \mathrm{VD}$ processed in the kidneys, was also measured. Interestingly, the level of $1,25(\mathrm{OH}) 2 \mathrm{VD}$ in the RYGB group was evidently increased, which was consistent with the results of Abegg et al. [37]. From their perspective, one possible explanation is that RYGB surgery leads to an ineffective duodenal vitamin $\mathrm{D}$ signal, which may lead to an increase in the 1,25 (OH)2VD level [48]. Another explanation is that enterocytes could promote renal 1-hydroxylase activity under the circumstance of decreased intestinal calcium concentrations, ultimately leading to a high level of 1,25(OH)2VD [49]. In our study, the level of FGF23 was decreased as well, which could be attributed to the decrease in serum phosphate [50]. A decrease or loss of function of FGF23 will, in turn, result in an increase in the 1,25(OH)2VD level [51].

This study has some limitations. First, even though the animal models can unify environmental factors and 
standardize experimental procedures, they cannot exactly mimic the actual course that happens in the human body. Second, we only evaluated the effect of bariatric surgery over a 4 -week period without setting other time points, which overlooked the dynamic change even in the short term. Third, an item-by-item comparison could not be conducted due to the lack of baseline data such as BMD and BTM. Lastly, body weight-matched groups were not set to identify the impact of body weight loss in this study.

\section{Conclusions}

Despite its excellent ability to provide short-term glycemic control, the RYGB procedure also led to severe impairment of bone health compared with the SG procedure. To be specific, the decrease in BMD could be the result of an increased bone turnover rate and lower levels of calcium and $1,25(\mathrm{OH})_{2} \mathrm{VD}$, among other factors. Adequate and timely calcium and vitamin $\mathrm{D}$ supplementation is proposed to avoid osteopenia and fracture risks after operation. Besides, DXA and BTM detection are needed in the early stage after bariatric surgery, especially for RYGB procedure. Further studies are needed to evaluate the specific regulatory mechanism of bone health change after bariatric surgery.

\section{Acknowledgement}

There are no acknowledgments to declare.

\section{Statement of Ethics}

This study was approved by Ethics Committee of Beijing Friendship Hospital (approval No.: BJFH-EC/2014-93). All experiments conformed to the Institutional Animal Care and Use guidelines with ethical review permissions.

\section{Conflict of Interest Statement}

The authors declare no conflict of interests.

\section{Funding Sources}

This work was supported by Capital Special Clinical Features (grant No.: Z151100004015065) and the National Natural Science Foundation of China (grant No.: 81902203).

\section{Author Contributions}

H.M. and J.L. conceived and designed the experiments. C.H., Q.Z., and B.Z. performed the experiments. Q.W. analyzed and interpreted the data. H.M. contributed reagents, materials, analysis tools or data. C.H. and Q.W. wrote this paper.

\section{References}

1 Buchwald H, Avidor Y, Braunwald E, Jensen MD, Pories W, Fahrbach K, et al. Bariatric surgery: a systematic review and meta-analysis. JAMA. 2004 Oct;292(14):1724-37.

2 Li JF, Lai DD, Ni B, Sun KX. Comparison of laparoscopic Roux-en-Y gastric bypass with laparoscopic sleeve gastrectomy for morbid obesity or type 2 diabetes mellitus: a metaanalysis of randomized controlled trials. Can J Surg. 2013 Dec;56(6):E158-64.

3 Mechanick JI, Youdim A, Jones DB, Timothy Garvey W, Hurley DL, Molly McMahon M, et al. Clinical practice guidelines for the perioperative nutritional, metabolic, and nonsurgical support of the bariatric surgery patient-2013 update: cosponsored by American Association of Clinical Endocrinologists, the Obesity Society, and American Society for Metabolic \& Bariatric Surgery. Surg Obes Relat Dis. 2013 Mar-Apr;9(2):159-91.

4 Buchwald $\mathrm{H}$. The evolution of metabolic/bariatric surgery. Obes Surg. 2014 Aug;24(8): 1126-35.
5 Wucher H, Ciangura C, Poitou C, Czernichow S. Effects of weight loss on bone status after bariatric surgery: association between adipokines and bone markers. Obes Surg. 2008 Jan;18(1):58-65.

6 Cornish J, Callon KE, Bava U, Lin C, Naot D, Hill BL, et al. Leptin directly regulates bone cell function in vitro and reduces bone fragility in vivo. J Endocrinol. 2002 Nov;175(2): 405-15.

7 Lenchik L, Register TC, Hsu FC, Lohman K, Nicklas BJ, Freedman BI, et al. Adiponectin as a novel determinant of bone mineral density and visceral fat. Bone. 2003 Oct;33(4):646-51.

8 Riis BJ, Rødbro P, Christiansen C. The role of serum concentrations of sex steroids and bone turnover in the development and occurrence of postmenopausal osteoporosis. Calcif Tissue Int. 1986 Jun;38(6):318-22.

9 Starup-Linde J, Eriksen SA, Lykkeboe S, Handberg A, Vestergaard P. Biochemical markers of bone turnover in diabetes patients-a meta-analysis, and a methodological study on the effects of glucose on bone markers. Osteoporos Int. 2014 Jun;25(6):1697-708.
10 Saito M, Fujii K, Mori Y, Marumo K. Role of collagen enzymatic and glycation induced cross-links as a determinant of bone quality in spontaneously diabetic WBN/Kob rats. Osteoporos Int. 2006 Oct;17(10):1514-23.

11 Rousseau C, Jean S, Gamache P, Lebel S, MacWay F, Biertho L, et al. Change in fracture risk and fracture pattern after bariatric surgery: nested case-control study. BMJ. 2016 Jul; 354:i3794.

12 Casagrande DS, Repetto G, Mottin CC, Shah J, Pietrobon R, Worni M, et al. Changes in bone mineral density in women following 1-year gastric bypass surgery. Obes Surg. 2012 Aug;22(8):1287-92.

13 Vilarrasa N, San José P, García I, Gómez-Vaquero C, Miras PM, de Gordejuela AG, et al. Evaluation of bone mineral density loss in morbidly obese women after gastric bypass: 3-year follow-up. Obes Surg. 2011 Apr;21(4): $465-72$. 
14 Ruiz-Tovar J, Oller I, Tomas A, Llavero C, Arroyo A, Calero A, et al. Midterm impact of sleeve gastrectomy, calibrated with a 50-Fr bougie, on weight loss, glucose homeostasis, lipid profiles, and comorbidities in morbidly obese patients. Am Surg. 2012 Sep;78(9):96974.

15 Ruiz-Tovar J, Oller I, Priego P, Arroyo A, Calero A, Diez M, et al. Short- and mid-term changes in bone mineral density after laparoscopic sleeve gastrectomy. Obes Surg. 2013 Jul;23(7):861-6.

16 Balsa JA, Botella-Carretero JI, Peromingo R, Caballero C, Muñoz-Malo T, Villafruela JJ, et al. Chronic increase of bone turnover markers after biliopancreatic diversion is related to secondary hyperparathyroidism and weight loss. Relation with bone mineral density. Obes Surg. 2010 Apr;20(4):468-73.

17 Scibora LM. Skeletal effects of bariatric surgery: examining bone loss, potential mechanisms and clinical relevance. Diabetes Obes Metab. 2014 Dec;16(12):1204-13.

18 Meguid MM, Ramos EJ, Suzuki S, Xu Y, George ZM, Das UN, et al. A surgical rat model of human Roux-en-Y gastric bypass. J Gastrointest Surg. 2004 Jul-Aug;8(5):621-30.

19 Eickhoff H, Louro TM, Matafome PN, Vasconcelos F, Seiça RM, Castro E Sousa F. Amelioration of glycemic control by sleeve gastrectomy and gastric bypass in a lean animal model of type 2 diabetes: restoration of gut hormone profile. Obes Surg. 2015 Jan;25(1): $7-18$.

20 de Bona Castelan J, Bettiol J, d'Acampora AJ, Castelan JV, de Souza JC, Bressiani V, et al. Sleeve gastrectomy model in Wistar rats. Obes Surg. 2007 Jul;17(7):957-61.

21 Hayoz C, Hermann T, Raptis DA, Brönnimann A, Peterli R, Zuber M. Comparison of metabolic outcomes in patients undergoing laparoscopic roux-en-Y gastric bypass versus sleeve gastrectomy - a systematic review and meta-analysis of randomised controlled trials. Swiss Med Wkly. 2018 Jul;148:w14633.

22 Wang K, Zhou X, Quach G, Lu J, Gao W, Xu A, et al. Effect of Sleeve Gastrectomy Plus Side-to-Side Jejunoileal Anastomosis for Type 2 Diabetes Control in an Obese Rat Model. Obes Surg. 2016 Apr;26(4):797-804.

23 Tothill P. Dual-energy x-ray absorptiometry measurements of total-body bone mineral during weight change. J Clin Densitom. 2005; 8(1):31-8.

24 Tothill P, Hannan WJ, Cowen S, Freeman CP. Anomalies in the measurement of changes in total-body bone mineral by dual-energy $\mathrm{X}$ ray absorptiometry during weight change. J Bone Miner Res. 1997 Nov;12(11):1908-21.

25 Van Loan MD. Is dual-energy X-ray absorptiometry ready for prime time in the clinical evaluation of body composition? Am J Clin Nutr. 1998 Dec;68(6):1155-6.

26 Schafer AL, Weaver CM, Black DM, Wheeler AL, Chang H, Szefc GV, et al. Intestinal calcium absorption decreases dramatically after gastric bypass surgery despite optimization of vitamin d status. J Bone Miner Res. 2015 Aug; 30(8):1377-85.

27 Yu EW, Lee MP, Landon JE, Lindeman KG, Kim SC. Fracture risk after bariatric surgery: Roux-en-Y gastric bypass versus adjustable gastric banding. J Bone Miner Res. 2017 Jun; 32(6):1229-36.

28 Walicka M, Czerwińska E, Tałałaj M, Marcinowska-Suchowierska E. [Influence of weight reduction on leptin concentration and bone mineral density in patients with morbid obesity before and 6 months after bariatric surgery]. Endokrynol Pol. 2009 Mar-Apr; 60(2):97-102.

29 Fleischer J, Stein EM, Bessler M, Della Badia M, Restuccia N, Olivero-Rivera L, et al. The decline in hip bone density after gastric bypass surgery is associated with extent of weight loss. J Clin Endocrinol Metab. 2008 Oct;93(10):3735-40.

30 Coates PS, Fernstrom JD, Fernstrom MH, Schauer PR, Greenspan SL. Gastric bypass surgery for morbid obesity leads to an increase in bone turnover and a decrease in bone mass. J Clin Endocrinol Metab. 2004 Mar;89(3):1061-5.

31 Lindeman KG, Greenblatt LB, Rourke C, Bouxsein ML, Finkelstein JS, Yu EW. Longitudinal 5-Year evaluation of bone density and microarchitecture after Roux-en-Y gastric bypass surgery. J Clin Endocrinol Metab. 2018 Nov; 103(11):4104-12.

32 Vilarrasa N, Gómez JM, Elio I, Gómez-Vaquero C, Masdevall C, Pujol J, et al. Evaluation of bone disease in morbidly obese women after gastric bypass and risk factors implicated in bone loss. Obes Surg. 2009 Jul;19(7): 860-6.

33 Pluskiewicz W, Bužga M, Holéczy P, Bortlík L, Šmajstrla V, Adamczyk P. Bone mineral changes in spine and proximal femur in individual obese women after laparoscopic sleeve gastrectomy: a short-term study. Obes Surg. 2012 Jul;22(7):1068-76.

34 Stein EM, Carrelli A, Young P, Bucovsky M, Zhang C, Schrope B, et al. Bariatric surgery results in cortical bone loss. J Clin Endocrinol Metab. 2013 Feb;98(2):541-9.

35 Hsin MC, Huang CK, Tai CM, Yeh LR, Kuo HC, Garg A. A case-matched study of the differences in bone mineral density 1 year after 3 different bariatric procedures. Surg Obes Relat Dis. 2015 Jan-Feb;11(1):181-5.

36 Bredella MA, Greenblatt LB, Eajazi A, Torriani M, Yu EW. Effects of Roux-en-Y gastric bypass and sleeve gastrectomy on bone mineral density and marrow adipose tissue. Bone. 2017 Feb;95:85-90.

37 Abegg K, Gehring N, Wagner CA, Liesegang A, Schiesser M, Bueter M, et al. Roux-en-Y gastric bypass surgery reduces bone mineral density and induces metabolic acidosis in rats. Am J Physiol Regul Integr Comp Physiol. 2013 Nov;305(9):R999-1009.

38 Li Z, Hardij J, Evers SS, Hutch CR, Choi SM, Shao Y, et al. G-CSF partially mediates effects of sleeve gastrectomy on the bone marrow niche. J Clin Invest. 2019 May;129(6):240416.

39 Vestergaard P. Discrepancies in bone mineral density and fracture risk in patients with type 1 and type 2 diabetes-a meta-analysis. Osteoporos Int. 2007 Apr;18(4):427-44.

40 Greenblatt MB, Tsai JN, Wein MN. Bone turnover markers in the diagnosis and monitoring of metabolic bone disease. Clin Chem. 2017 Feb;63(2):464-74.

41 Stein EM, Silverberg SJ. Bone loss after bariatric surgery: causes, consequences, and management. Lancet Diabetes Endocrinol. 2014 Feb;2(2):165-74.

42 Yu EW, Wewalka M, Ding SA, Simonson DC, Foster K, Holst JJ, et al. Effects of Gastric Bypass and Gastric Banding on Bone Remodeling in Obese Patients With Type 2 Diabetes. J Clin Endocrinol Metab. 2016 Feb;101(2): 714-22.

43 Muschitz C, Kocijan R, Marterer C, Nia AR, Muschitz GK, Resch H, et al. Sclerostin levels and changes in bone metabolism after bariatric surgery. J Clin Endocrinol Metab. 2015 Mar;100(3):891-901.

44 Crawford MR, Pham N, Khan L, Bena JF, Schauer PR, Kashyap SR. Increased bone turnover in type 2 diabetes patients randomized to bariatric surgery versus medical therapy at 5 years. Endocr Pract. 2018 Mar;24(3): 256-64.

45 Grethen E, Hill KM, Jones R, Cacucci BM, Gupta CE, Acton A, et al. Serum leptin, parathyroid hormone, 1,25-dihydroxyvitamin $\mathrm{D}$, fibroblast growth factor 23, bone alkaline phosphatase, and sclerostin relationships in obesity. J Clin Endocrinol Metab. 2012 May; 97(5):1655-62.

46 Yu EW, Thomas BJ, Brown JK, Finkelstein JS. Simulated increases in body fat and errors in bone mineral density measurements by DXA and QCT. J Bone Miner Res. 2012 Jan;27(1): 119-24.

47 Wortsman J, Matsuoka LY, Chen TC, Lu Z, Holick MF. Decreased bioavailability of vitamin D in obesity. Am J Clin Nutr. 2000 Sep; 72(3):690-3.

48 Lieben L, Masuyama R, Torrekens S, Van Looveren R, Schrooten J, Baatsen P, et al. Normocalcemia is maintained in mice under conditions of calcium malabsorption by vitamin D-induced inhibition of bone mineralization. J Clin Invest. 2012 May;122(5):1803-15.

49 Miao D, He B, Lanske B, Bai XY, Tong XK, Hendy GN, et al. Skeletal abnormalities in Pth-null mice are influenced by dietary calcium. Endocrinology. 2004 Apr;145(4):204653.

50 Antoniucci DM, Yamashita T, Portale AA. Dietary phosphorus regulates serum fibroblast growth factor-23 concentrations in healthy men. J Clin Endocrinol Metab. 2006 Aug;91(8):3144-9.

51 Quarles LD. Role of FGF23 in vitamin D and phosphate metabolism: implications in chronic kidney disease. Exp Cell Res. 2012 May;318(9):1040-8. 